\title{
Improved method to measure urinary alkoxyacetic acids
}

\author{
Tung-Sheng Shih, Jui-Shu Chou, Cheng-Yao Chen, Thomas J Smith
}

\begin{abstract}
Objectives-To simplify the current preparation of samples, and to improve the specificity and reliability of the conventional analytical methods to measure urinary alkoxyacetic acids.

Methods-Samples containing alkoxyacetic acids including methoxy, ethoxy, and butoxyacetic acids (MAA, EAA, and BAA) were acidified with $\mathrm{HCl}$ and extracted with a mixed solvent of methylene chloride and isopropyl alcohol, then analysed by gas chromatography/mass spectrometry (GC/MS).

Results-Optimal results were obtained when $\mathrm{pH}$ was $1.05-1.45$, the ratio of methylene chloride and isopropyl alcohol was $2: 1$, and when extraction time was $10 \mathrm{~min}$ utes. Over the concentration range 0.3-200 $\mu \mathrm{g} / \mathrm{ml}$, MAA, EAA, and BAA could be determined with a pooled coefficient of variation (nine concentrations, six replicate samples) of $5.55 \%, 6.37 \%$, and $6.41 \%$, respectively. Urine samples were stable for at least 5 months and 3 freeze-thaw cycles at $-20^{\circ} \mathrm{C}$. The limits of detection of MAA, EAA, and BAA were $0.055,0.183$, and $0.009 \mu \mathrm{g} / \mathrm{ml}$, respectively. The matrix effect of urine samples was negligible for MAA and EAA, but were marginally significant for BAA. The average recoveries of alkoxyacetic acids were $99 \%-101 \%$. In urine samples MAA from 15 exposed workers showed a strong linear correlation $(r=0.999$, slope $=1.01)$ between the new GC/MS method and Sakai's GC method. Conclusions-The simplified non-derivatisation pretreatment of samples coupled with GC/MS can provide a specific, sensitive, simple, safe, and reliable method for the biological monitoring of occupational exposure of ethylene glycol ethers.

(Occup Environ Med 1999;56:460-467)
\end{abstract}

Keywords: alkoxyacetic acids, ethylene glycol ethers, biological monitoring

The ethylene glycol ethers, such as 2-methoxyethanol, 2-ethoxyethanol, and 2-butoxyethanol and their acetates are widely used as industrial solvents because of their excellent chemical and physical properties. ${ }^{1}$ Animal studies and case reports have found that ethylene glycol ethers can cause strong haematological, developmental, and reproductive effects through inhalation, dermal absorption, and ingestion. ${ }^{2-6}$ Metabolic studies showed that ethylene glycol ethers are mainly metabolised to their corresponding alkoxyacetic acids, methoxyacetic acid (MAA), ethoxyacetic acid (EAA), and butoxyacetic acid (BAA) through alcohol dehydrogenase and aldehyde dehydrogenase. ${ }^{7}$ In vitro studies showed that ethylene glycol ethers themselves evoke no toxic responses in either Sertoli cell culture $^{8}$ or in rat whole embryo culture, ${ }^{9}$ whereas the corresponding alkoxyacetic acids do. In vivo studies showed that equivalent doses of ethylene glycol ethers and their corresponding metabolite alkoxyacetic acids are equally effective in causing adverse effects. ${ }^{10}{ }^{11}$ Alkoxyacetic acids have been found to be the main metabolites in the urine of both tested animals and humans occupationally or experimentally exposed to ethylene glycol ethers. ${ }^{12-16}$ Thus, it is suggested that alkoxyacetic acids are the toxicants of exposure to ethylene glycol ethers that produce these health effects. Several studies also found that skin absorption could be the main route of entry of ethylene glycol ethers, and that traditional environmental monitoring for air contamination might not be able to evaluate the total dose from all routes of exposure. ${ }^{17-19}$ These findings suggest that measurement of urinary alkoxyacetic acids can be viewed as an indicator of potential health effects as well as an assessment of total uptake through both inhalation and dermal absorption. ${ }^{1}$

Several methods of biological monitoring to measure the urinary alkoxyacetic acids have been published. ${ }^{20-30}$ Lyophilisation, counter ion pair, liquid-solid phase extraction, derivatisation with pentafluorobenzyl bromide, diaozomethane, and trimethylsilyldiazomethane were most commonly used in the pretreatment of samples. However, pentafluorobenzyl bromide derivatisation can generate a very irritating gas, hydrogen bromide. Diazomethane derivatisation is hazardous for laboratory chemists. ${ }^{24}$ Trimethylsilyldiazomethane is very expensive and the impurity in products from different manufacturers might cause interference in analysis of alkoxyacetic acids. Lyophilisation and liquid-solid phase extraction are time consuming, expensive, and require considerably more sample preparation steps.

Flame ionisation detectors (FIDs), and electron capture detectors (ECDs) are commonly used in the current methods, but they are not specific. The ECD is very sensitive for compounds containing halogen, but further isolation steps have to be applied to remove reagents containing halogen and contaminants to avoid interference, and the total method error is much higher. Large variation and matrix effects were also noticed in measurement of urinary MAA 
with the GC/ECD method. ${ }^{24}$ Wittfoht et al used N-methyl-N-(tert-butyl-dimethyl-silyl)trifluoro-acetamide and the gas chromatography/mass spectrometry (GC/MS) method to measure urinary MAA. ${ }^{26}$ That method is sensitive and specific compared with other existing methods. However, the time consuming pretreatment of the samples make it less efficient. Negative chemical ionisation mode GC/MS was used to measure the extremely low concentrations of 2-butoxyethanol and BAA in human blood and urine samples. ${ }^{17} 290$ The negative chemical ionisation needs more complex analytical skill and expensive equipment, and is not available in many research or service laboratories. The deuterated internal standards used are very expensive and not commercially available in Taiwan. Besides these problems, most of the existing methods were not validated either in different laboratories or by different analytical methods or field samples.

The main purposes of this study were to simplify the preparation of samples, to improve the specificity and reliability of the existing analytical methods, and to provide adequate laboratory and field validation data on a new GC/MS method. In this study, urinary MAA, $\mathrm{EAA}$, and BAA, the main metabolites of the three most popularly used ethylene glycol ethers (2-methoxyethanol, 2-ethoxyethanol,
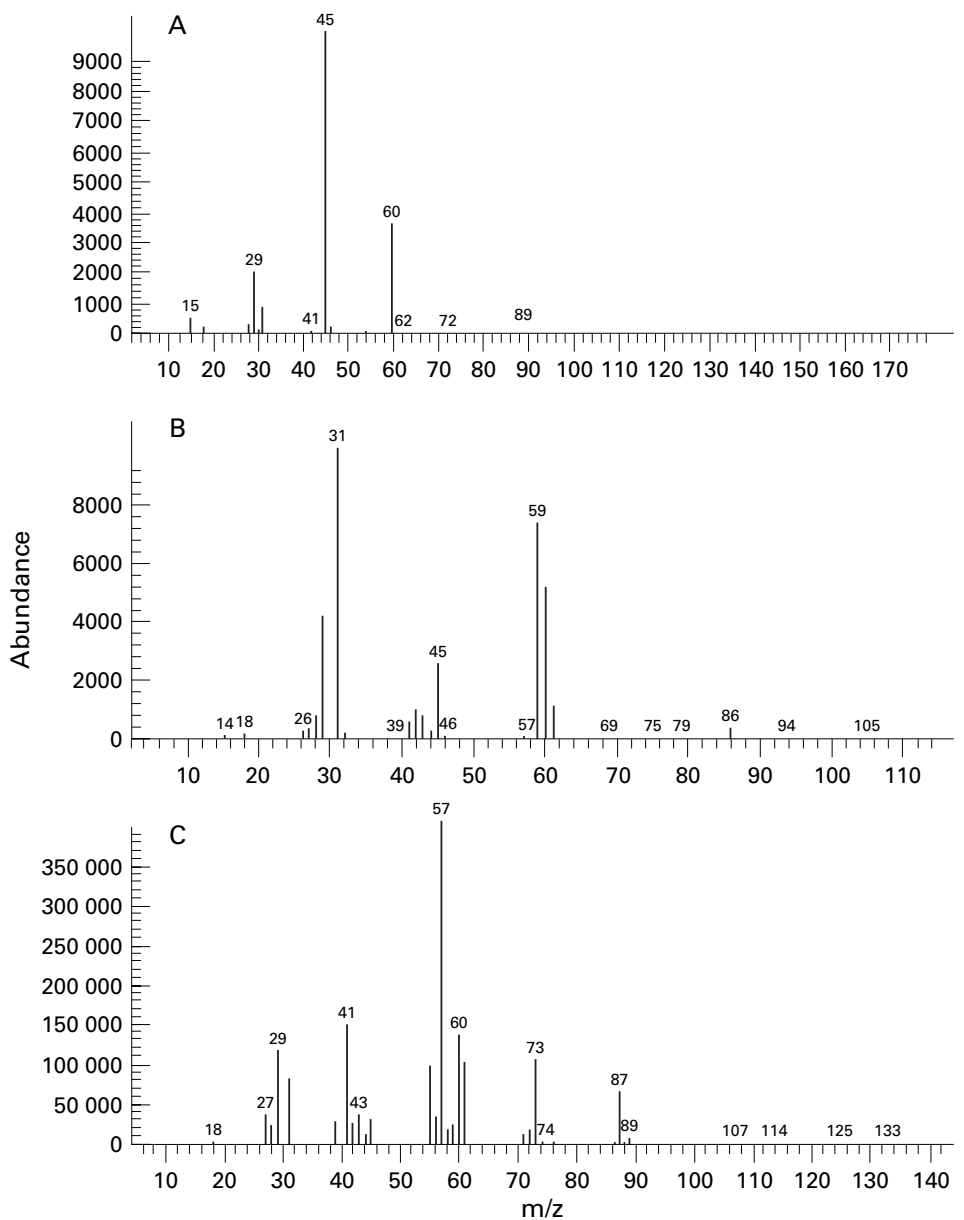

Figure 1 Mass spectra of $(A)$ methoxyacetic acid $(M A A),(B)$ ethoxyacetic acid $(E A A)$, and $(C)$ butoxyacetic acid (BAA) in urine samples. All those spectra have been confirmed by the reference mass spectra. and 2-butoxyethanol), were chosen as the target research chemicals.

\section{Materials and methods}

REAGENTS

Chemicals used in this study were MAA (98\%, E Merck, Darmstadt, Germany), EAA (98\%, E Merck), isopropyl alcohol (99.7\%, E Merck), methylene chloride (99.7\%, E Merck), $\mathrm{HCl}$ (37\%, E Merck), and internal standard dichlorobenzene $(99 \%, \mathrm{E}$ Merck) and BAA (> 99\%, Acros, NJ, USA).

\section{SAMPLE PREPARATION}

Pooled urine samples from more than six healthy non-exposed people were used as the matrix blank. Concentrated $\mathrm{HCl}(60 \mu \mathrm{l})$ was added to $1 \mathrm{ml}$ urine spiked with $120 \mu \mathrm{g} / \mathrm{ml}$ MAA, EAA, and BAA. The MAA, EAA, and BAA were extracted for 10 minutes by an orbital shaker (TKS, Model OS-701, Taipei, Taiwan) with $1 \mathrm{ml}$ of mixed solvents of methylene chloride and isopropyl alcohol $(2: 1 \mathrm{v} / \mathrm{v})$, containing $0.005 \mu \mathrm{l} / \mathrm{ml}$ internal standard dichlorobenzene. After mixing and centrifuging at $3000 \mathrm{rpm}$ for 5 minutes, the lower organic layer was transferred to a $1.5 \mathrm{ml}$ vial, and $2 \mu \mathrm{l}$ of this organic layer was injected into the GC/MS apparatus for analysis.

\section{SAMPLE ANALYSIS}

The MAA, EAA, and BAA samples were analysed by GC/MS (Hewlett Packard, G1,800A, GCD, CA, USA) equipped with an HP 7673A automatic sampler and a capillary column (J and W DB Wax, $60 \mathrm{~m} \times 0.25 \mathrm{~mm}$ ID, $0.25 \mathrm{~m}$ film thickness, CA, USA). The oven temperature was initially maintained at $60^{\circ} \mathrm{C}$ for 5 minutes, then was programmed to $195^{\circ} \mathrm{C}$ at $10^{\circ} \mathrm{C} /$ minutes, held at $195^{\circ} \mathrm{C}$ for 1 minute, programmed again to $205^{\circ} \mathrm{C}$ at $10^{\circ} \mathrm{C} / \mathrm{min}$, held at $205^{\circ} \mathrm{C}$ for $5 \mathrm{~min}$, and was finally programmed to $220^{\circ} \mathrm{C}$ at $5^{\circ} \mathrm{C} /$ minute, and held at $220^{\circ} \mathrm{C}$ for 2 minutes. The injector temperature was set at $210^{\circ} \mathrm{C}$, and the detector temperature was at $260^{\circ} \mathrm{C}$. Aliquots of $2 \mu \mathrm{l}$ extraction solvents were automatically injected at 33 minute intervals. Splitless mode was used, and the flow rate of helium carrier gas was 1 $\mathrm{ml} /$ minute.

Electron energy used for mass spectrometry was $70 \mathrm{eV}$. Mass spectra (fig 1) were first used for qualitative confirmation of MAA, EAA, $\mathrm{BAA}$, and the internal standard. Selected ion monitoring mode was then used for quantitative measurement based on the abundance ratio of the major fragments of MAA (m/z 45), EAA $(\mathrm{m} / \mathrm{z} 31)$, BAA $(\mathrm{m} / \mathrm{z} 57)$ with respect to the major fragment of internal standard dichlorobenzene ( $\mathrm{m} / \mathrm{z}$ 146). Qualitative confirmation was checked by the abundance ratio of the secondary to the primary fragment peaks of MAA (m/z 60:45), EAA (m/z 59:31), BAA $(\mathrm{m} / \mathrm{z} 41: 57)$, and for the internal standard $(\mathrm{m} / \mathrm{z}$ 148:146) in selected ion monitoring. 
EXAMINATION OF THE OPTIMAL PRETREATMENT OF SAMPLES

The alkoxyacetic acids are highly water and lipid soluble, and most when dissolved in urine are in ionised form. The addition of $\mathrm{HCl}$ can convert the ionised forms of alkoxyacetic acids to non-ionised form for better solvent extraction. Extraction procedures which give the highest response on GC/MS are chosen as the optimal conditions. The main variables examined in this study were $\mathrm{pH}$ value, ratio of mixed extraction solvents, and extraction time. Calibration curves between and within days, recovery, precision, and matrix effects were tested. Sample storage stability included testing 3 freeze-thaw cycles. Limits of detection (mean $+3 \mathrm{SD}$ of the blank baseline signals divided by the slope of the standard curve) and limits of measurement (mean $+10 \mathrm{SD}$ of the blank baseline signal divided by the slope of the standard curve $)^{31}$ with and without derivatisation procedures were also examined in this study. The lowest concentration of the standard curve was chosen as the lowest reliable measurement when the correlation coefficient was greater than 0.995 , the relative error and coefficient of variation were $<15 \%$, the signal over noise ratio was $>4$, and the ratio of the secondary to the primary fragments of alkoxyacetic acids was within $20 \%$ of that in the reference mass spectra.

METHOD COMPARISON

Urine samples were collected from 19 workers exposed to 2-methoxyethanol in a semiconductor copper laminate circuit board manufacturing plant and were separated into six aliquots after 5 minutes of mixing. They were stored at $-20^{\circ} \mathrm{C}$ before analysis. A previously validated GC/FID method, ${ }^{25}$ was used as the reference method to compare with our GC/MS method. The procedures are summarised as follows: 0.1 $\mathrm{ml}$ BAA (internal standard, $10.17 \mathrm{~g} / \mathrm{ml}$ ), was added to $1 \mathrm{ml}$ urine, which was acidified with $0.1 \mathrm{ml}$ concentrated $\mathrm{HCl}$. The MAA and EAA were then extracted for 10 minutes by an orbital shaker with $1 \mathrm{ml}$ of the mixture of $2: 1$ (v/v) methylene chloride and isopropyl alcohol. After centrifuging at $3000 \mathrm{rpm}$ for 5 minutes, $0.5 \mathrm{ml}$ of the lower organic layer was transferred to a $1.5 \mathrm{ml}$ vial, and was derivatised with $25 \mu \mathrm{l}$ of a solution of trimethylsilyldiazomethane $(2.0 \mathrm{M}$ solution in hexane, Aldrich, WI, USA). The esterified acid solution was analysed by a GC (Hewlett-Packard 5890 Series II, CA, USA) equipped with an HP 7673A autosampler and an FID. A magabore column ( $\mathrm{J}$ and W DB-WAX, $30 \mathrm{~m} \times 0.53 \mathrm{~mm}$, $1.0 \mathrm{~m}$ film thickness, CA, USA) was used. The oven temperature was initially maintained at $50^{\circ} \mathrm{C}$ for 2 minutes, then was programmed to $65^{\circ} \mathrm{C}$ at $5^{\circ} \mathrm{C} / \mathrm{min}$, programmed again to $130^{\circ} \mathrm{C}$ at $10^{\circ} \mathrm{C} / \mathrm{min}$, held at $130^{\circ} \mathrm{C}$ for 8 minutes, then finally programmed to $225^{\circ} \mathrm{C}$ at $25^{\circ} \mathrm{C} / \mathrm{min}$, and held at $225^{\circ} \mathrm{C}$ for 10 minutes. The injection temperature was $220^{\circ} \mathrm{C}$, and the detector temperature was $230^{\circ} \mathrm{C}$. Of the esterified acid solution 21 were injected into the GC apparatus after 30 minutes stirring by an orbital shaker. The flow rate of nitrogen carrier gas was $13 \mathrm{ml} / \mathrm{min}$, air flow was $300 \mathrm{ml} / \mathrm{min}$, and hydrogen flow was $30 \mathrm{ml} / \mathrm{min}$. The concentration range of the standard curves for MAA and EAA was 3.5 to $200 \mu \mathrm{g} / \mathrm{ml}$.

\section{DATA ANALYSIS}

The GC/MS response, either the abundance of the main fragment or the ratio of the abundance of the main fragment to that of the internal standard, was expressed as mean (SD) of triplicate analyses. As replicate analyses performed on an industrial hygiene sample are usually normally distributed, ${ }^{32}$ one way analysis of variance (ANOVA) and Tukey's pair wise tests were used to compare the differences among different conditions of analytical variables such as $\mathrm{pH}$ values, extraction time, and extraction solvent combination. A Wilcoxon non-parametric test was also used to evaluate the results. Eleven concentrations of standard solutions and simple linear regression were used to establish the standard curves. Analysis of covariance (ANCOVA) was used to test for the differences between slopes of standard curves with different matrices (deionisation water and urine matrices). Linear regression, the plot of concentration difference versus mean concentration of two methods, and the limits of agreement ${ }^{33} 34$ were used for the comparison of the new GC/MS method and the reference method. Pooled coefficients of variation (CV) across different concentrations were used to show the precision of the new GC/MS method. $^{31}$

\section{Results}

STANDARD CURVES AND GC/MS SPECTRA

Three standard curves between days and three standard curves within days were obtained for MAA, EAA, and BAA in the concentration range of $0.3 \mu \mathrm{g} / \mathrm{ml}$ to $200 \mu \mathrm{g} / \mathrm{ml}$ (the concentration range of the calibration curves for MAA was $0.15 \mu \mathrm{g} / \mathrm{ml}$ to $200 \mu \mathrm{g} / \mathrm{ml}$ ). For these a concentration ranges, the correlation coefficients of standard curves between the GC/MS response and the concentrations of MAA, EAA, and BAA were all $>0.997$. The pooled coefficients of variation (CVs) of the calibration curves within days (11 concentrations) were $5.48 \%(1.26 \%-12.87 \%), 6.59 \%(1.41 \%-$ $17.44 \%)$ and $6.17 \%(2.59 \%-12.09 \%)$ for MAA, EAA, and BAA, respectively $(n=3)$. The pooled CVs of calibration curves between days (11 concentrations) were $5.50 \% \quad(0.42 \%-$ $12.44 \%), 5.58 \%(0.17 \%-12.53 \%)$ and $4.62 \%$ $(0.64 \%-14.26 \%)$ for MAA, EAA, and BAA respectively $(n=3)$.

Figure 2 shows the gas chromatograms of blank and spiked urine samples. MAA, EAA, and BAA, and the internal standard were completely separated by the column under the analytical conditions. No interfering chemicals were found in GC or MS of urine samples. The mean (SD) retention times of MAA, EAA, BAA, and internal standard were 21.452 (0.005), 21.780 (0.003), 24.745 (0.005), and $16.548(0.001)$ minutes, respectively $(n=12)$. The MAA, EAA, BAA, and internal standard were reconfirmed by matching the MS of urine 


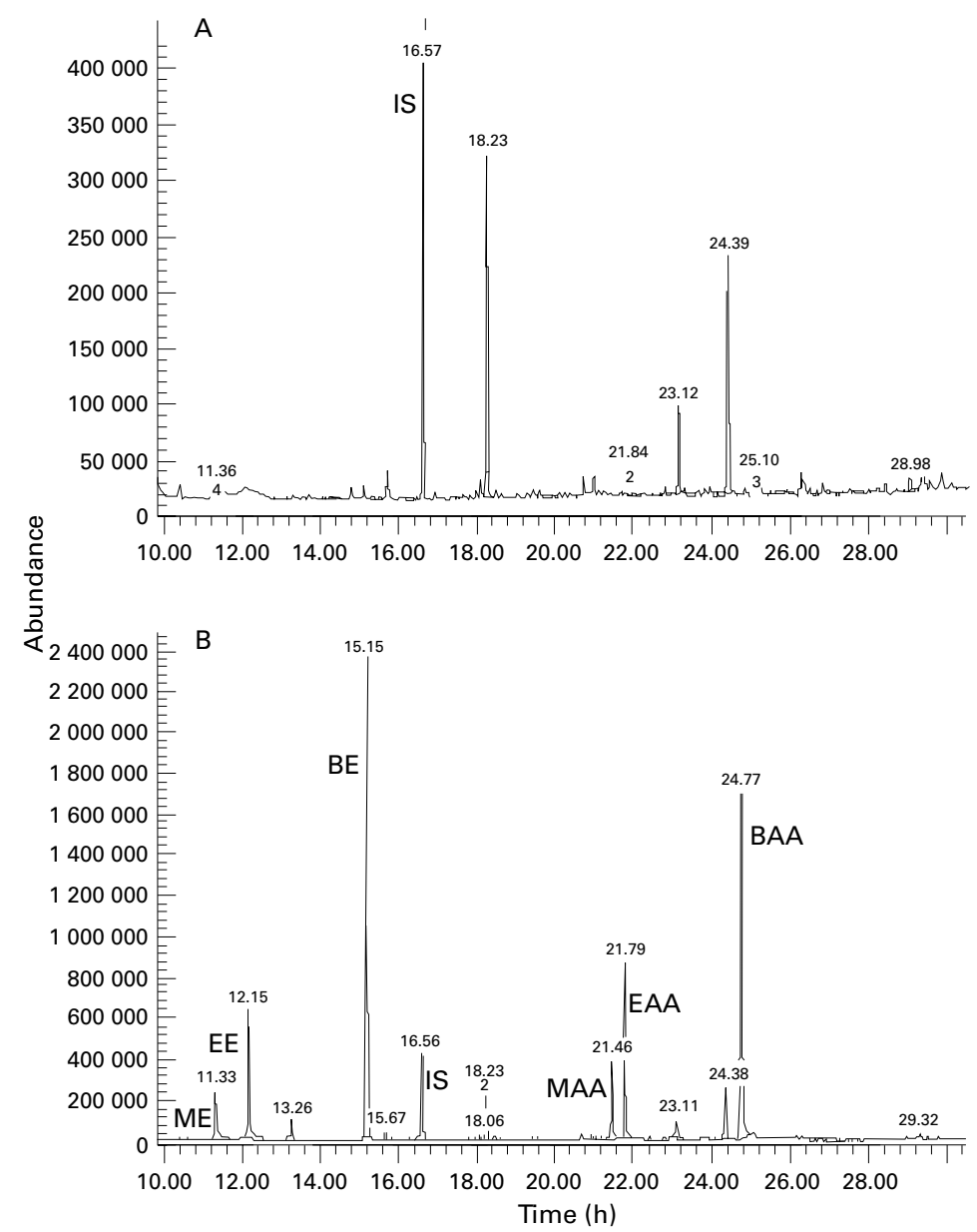

Figure 2 (A) Gas chromatogram of urine blank samples spiked with internal standard. (B) Gas chromatogram of 2-methoxyethanol (ME), 2-ethoxyethanol (EE),

2-butoxyethanol (BE), methoxyacetic acid $(M A A)$, ethoxyacetic acid (EAA), butoxyacetic acid (BAA), and internal standard (IS) dichlorobenzene in a urine sample. The

concentration of alkoxyacetic acids spiked was $110 \mu \mathrm{g} / \mathrm{ml}$. samples (fig 1) against the data bank reference spectra.

PRETREATMENT OF THE SAMPLES

Ratio of extraction solvents

Urine samples spiked with $120 \mathrm{~g} / \mathrm{ml}$ MAA, $\mathrm{EAA}$, and $\mathrm{BAA}$, were acidified to a $\mathrm{pH}$ of 1.05 with $60 \mu \mathrm{l}$ concentrated $\mathrm{HCl}$ and were extracted separately with $1 \mathrm{ml}$ of pure methylene chloride, pure isopropyl alcohol, and a mixed solvent with different ratio of methylene chloride and isopropyl alcohol that ranged from $1: 1$ to $5: 1(\mathrm{v} / \mathrm{v})$ for 10 minutes. Figure 3 showed that the main fragment abundance of alkoxyacetic acids was influenced $(\mathrm{p}<0.05)$ by the different ratio of methylene chloride and isopropyl alcohol. The maximal abundance within the experiment tested in this study was found at a ratio of $2: 1$.

\section{Extraction time}

Urine samples spiked with $120 \mu \mathrm{g} / \mathrm{ml} \mathrm{MAA}$, EAA, and BAA, were acidified to a $\mathrm{pH}$ of 1.05 with $60 \mu \mathrm{l}$ concentrated $\mathrm{HCl}$ and were extracted with $1 \mathrm{ml}$ methylene chloride and isopropyl alcohol $(2: 1, \mathrm{v} / \mathrm{v})$ with $2,5,10$, and 20 minute extraction times. The ANOVA and Tukey's pairwise tests showed the ratio of main fragment abundance of the alkoxyacetic acids to the internal standard was significantly different between 2 minutes and other extraction time intervals for MAA $(p=0.024)$ and BAA $(p=0.016)$, but not significantly different for EAA $(p=0.055)$. There were no significant differences among 5, 10, and 20 minute extraction times $(p=0.10$ for all three alkoxyacetic acids) by ANOVA and Wilcoxon nonparametric tests. Figure 4 showed that the extraction efficiency became stable after 5 minutes of extraction. As 10 minutes of extraction will slightly improve efficiency and maybe also reduce the fraction of the method error
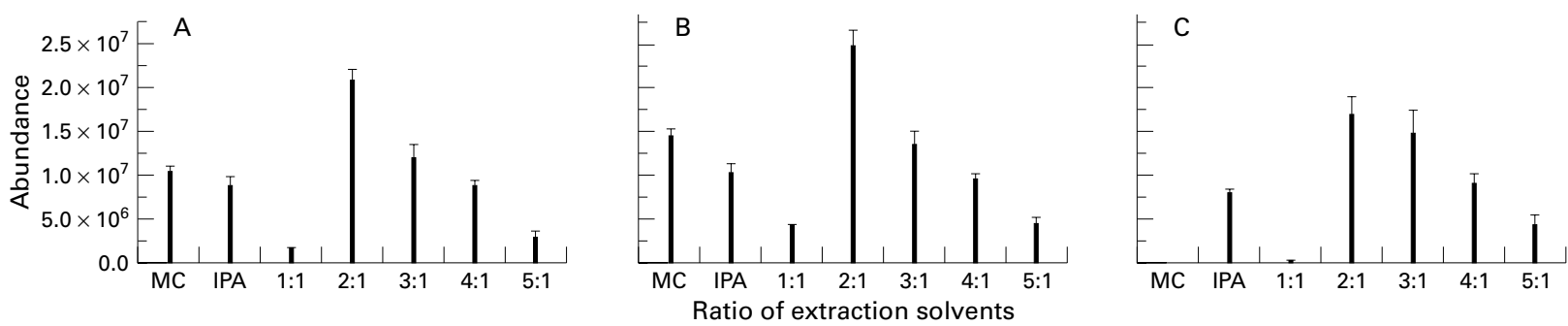

Figure 3 Influence of different ratio of extraction solvents: (A) methoxyacetic acid; (B) ethoxyacetic acid; and (C) butoxyacetic acid. Analyte concentration is $120 \mu \mathrm{g} / \mathrm{ml}$, pH was 1.05, and extraction time was 10 minutes. Data are means (SDs) of triplicates. Selective ion monitoring was used to measure alkoxyacetic acids.
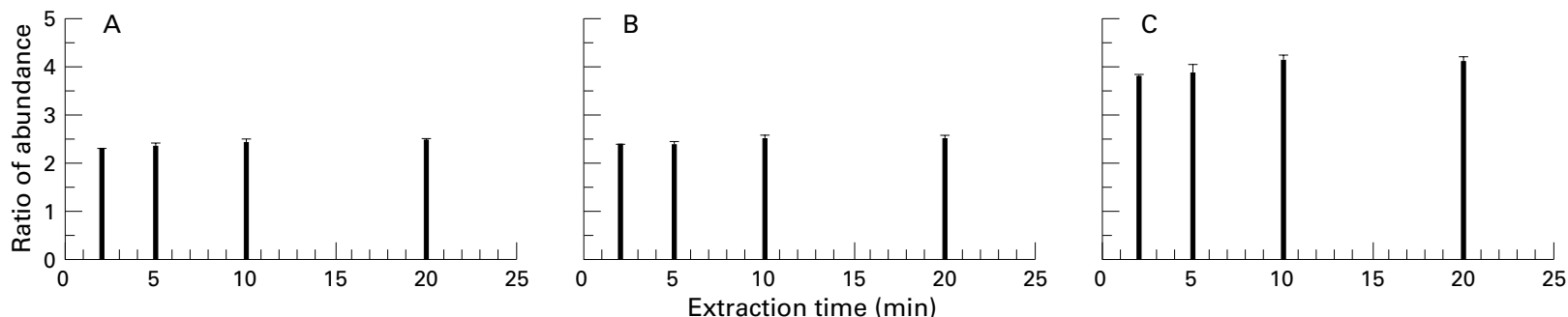

Figure 4 Influence of different extraction times of (A) methoxyacetic acid, (B) ethoxyacetic acid, and (C) butoxyacetic acid. Analyte concentration was $120 \mu \mathrm{g} / \mathrm{ml}$, ratio of methylene chloride (MC) and isopropyl alcohol (IPA) was 2:1 (v:v), and pH was 1.05. Data are means (SDs) of triplicates. Selective ion monitoring was used to measure alkoxyacetic acids. 

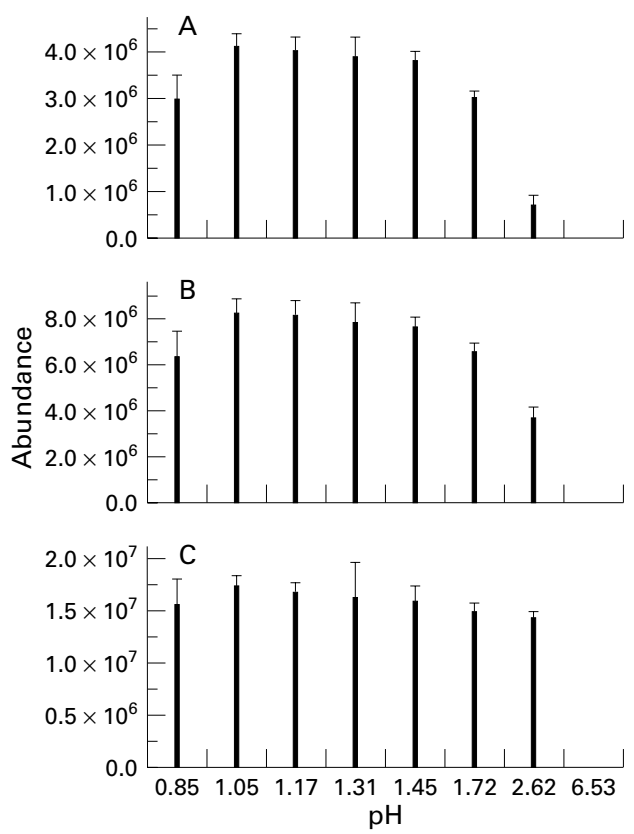

Figure 5 Influence of urinary $p H$ on $(A)$ methoxyacetic acid, (B) ethoxyacetic acid, and (C) butoxyacetic acid. Analyte concentration was $120 \mu \mathrm{g} / \mathrm{ml}$, ratio of methylene chloride $(M C)$ and isopropyl alcohol (IPA) was 2:1 (v:v), and extraction time was 10 minutes. Data are means $(S D s)$ of triplicates. Selective ion monitoring was used to measure alkoxyacetic acids.

caused by incomplete extraction, 10 minutes was chosen as the optimal extraction time.

\section{pH Value}

Urine samples spiked with $120 \mu \mathrm{g} / \mathrm{ml}$ MAA, EAA, and BAA, were acidified with different quantities of concentrated $\mathrm{HCl}$ and were extracted with $1 \mathrm{ml}$ of methylene chloride and isopropyl alcohol $(2: 1, \mathrm{v} / \mathrm{v})$ for 10 minutes. The ANOVA and Tukey's pairwise tests showed that no significant differences existed over a $\mathrm{pH}$ range of 1.45-1.05 for MAA, $\mathrm{pH} 1.45-0.85$ for $\mathrm{EAA}$, and $\mathrm{pH} 2.62-0.85$ for $\mathrm{BAA}$, as shown in figure 5 . There were no significant differences at $\mathrm{pH} 1.45-1.05$ ( $\mathrm{p}=0.60$ for all three alkoxyacetic acids) by ANOVA and Wilcoxon nonparametric tests. A pH of 1.05 was therefore chosen for the simultaneous analyses of three alkoxyacetic acids.

\section{PRECISION}

Nine concentrations of MAA, EAA, and BAA $(1.15,2.30,5.76,11.52,23.04,40.32,84,144$, and $200 \mu \mathrm{g} / \mathrm{ml}$ ) representing the range to be expected for biological samples were examined. Six replicate samples at each concentration showed that the pooled CVs for MAA, $\mathrm{EAA}$, and BAA were $5.55 \%(3.17 \%-8.24 \%)$, $6.37 \%(4.13 \%-9.15 \%)$, and $6.41 \%(4.08 \%-$ $8.77 \%$ ), respectively, and the CVs showed no evidence of dependence on concentration.

\section{MATRIX EFFECTS}

Deionised water and non-exposed human pooled urine were used for matrix effect comparison of MAA, EAA, and BAA. The ANCOVA analysis showed no significant differences between the slopes of deionised water and urine matrix $(0.05<\mathrm{p}<0.10)$ for MAA and
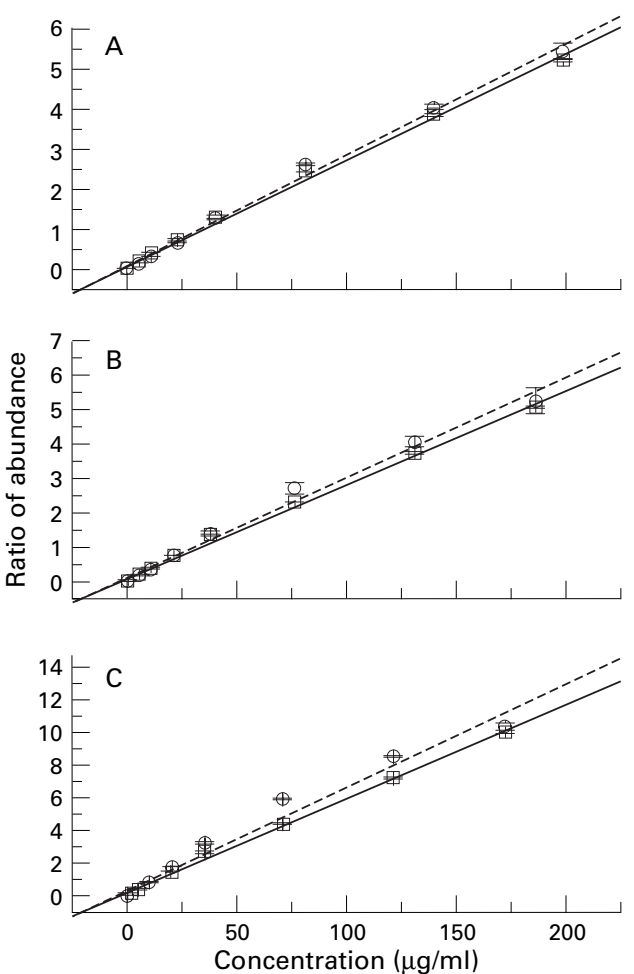

Figure 6 Influence of matrix effects on $(A)$ methoxyacetic acid, (B) ethoxyacetic acid, and (C) butoxyacetic acid. Data are means (SDs) of triplicates. Ratio of abundance represents the abundance ratio of main fragments of alkoxyacetic acids to that of internal standard. Selective ion monitoring was used to measure alkoxyacetic acids. Solid lines and square symbols represent the data in urine. Dotted lines and circle symbols represent the data in deionised water.

EAA, and a significant matrix effect for BAA $(0.02<p<0.05)$, in the concentration range of $0.3 \mu \mathrm{g} / \mathrm{ml}$ to $200 \mu \mathrm{g} / \mathrm{ml}$, as shown in figure 6 . The ratio of the slopes of standard curves between urine and deionisation water were 0.95, 0.93, and 0.91 for MAA, EAA, and BAA, respectively.

SENSITIVITY

The limits of detection of this new GC/MS method were $0.055 \mu \mathrm{g} / \mathrm{ml}$ for MAA; 0.183 $\mu \mathrm{g} / \mathrm{ml}$ for EAA; and $0.009 \mu \mathrm{g} / \mathrm{ml}$, for BAA respectively, and the limits of measurement were $0.136 \mu \mathrm{g} / \mathrm{ml}$ for MAA, $0.442 \mu \mathrm{g} / \mathrm{ml}$ for EAA, and $0.018 \mu \mathrm{g} / \mathrm{ml}$ for BAA, respectively. The concentration ranges of the standard curves of the new GC/MS method with and without the trimethylsilyldiazomethane derivatisation procedures were the same, $0.3-200$ $\mu \mathrm{g} / \mathrm{ml}$.

\section{RECOVERY}

The mean (SD) recoveries of MAA, EAA, BAA in spiked urine quality control samples of three concentrations $(23,84$, and $144 \mu \mathrm{g} / \mathrm{ml})$ were $100.8 \%(5.6 \%)$ (triplicate analyses for each concentration), $100.0 \%$ (4.3\%), and $98.6 \%$ $(2.4 \%)$, respectively.

\section{SAMPLE STABILITY TEST}

Storage stability

Twenty one spiked quality control samples with three concentrations $(24,59$, and 118 $\mu \mathrm{g} / \mathrm{ml}$ ) were prepared and stored at $-20^{\circ} \mathrm{C}$ for 
the sample stability test. Three samples were analysed in triplicate at days $0,7,9,15,50$, 115 , and 150 for storage stability. The results showed that MAA was stable for at least 5 months at $-20{ }^{\circ} \mathrm{C}$. The overall recovery of MAA was $101.63 \%$ (0.99\%) (mean (SD), triplicate analyses).

Freeze-thaw cycles

Eighteen spiked quality control samples with three concentrations were prepared and stored as mentioned above. Three freeze-thaw cycles showed that the overall recovery of MAA was $94.50 \%(2.13 \%)$ (mean (SD), triplicate analyses).

VALIDATION OF THE REFERENCE METHOD

Sixty four sets of triplicate analyses of urinary MAA of the workers in a semiconductor copper laminate circuit board manufacturing plant showed a pooled CV of $3.07 \%(0.30 \%-$ $7.76 \%$ ) over the concentration range of 6.27 $239 \mu \mathrm{g} / \mathrm{ml}$ by the reference method (unpublished data). Thirteen sets of triplicate analyses of urinary EAA of the workers in a screen printing factory showed a pooled CV of $5.66 \%$ $(0.66 \%-12.45 \%)$ over the concentration range of $6.80-185 \mu \mathrm{g} / \mathrm{ml}$ in our previous field study (unpublished data). The mean (SD) recoveries of blind quality control samples for MAA $(n=20)$ and EAA $(n=19)$ were $100.8 \%(3.8 \%)$, and $106.4 \%(6.8 \%)$, respectively. The mean (SD) recoveries of MAA proficiency analytical testing (PAT) samples from two other reference laboratories were $100.5 \%(7.3 \%)(n=24)$, and $105.5 \%(6.6 \%)(n=23)$ respectively in our previous validation study between laboratories. $^{38}$ All these data showed the excellent reliability of the reference method.

COMPARISON OF THE METHODS

Linear regression of 15 urine samples from exposed workers depicted a strong correlation $\left(r=0.999 ; \beta_{\mathrm{o}}=-1.75,0.75 ; \beta_{1}=1.01,0.01\right)$ between results from the GC/MS and the reference method over the concentration range of 3.57 to $228 \mu \mathrm{g} / \mathrm{ml}$. For the remaining four urine samples, the low MAA concentrations $(0.54-2.49 \mu \mathrm{g} / \mathrm{ml})$ could only be detected by the new GC/MS method. (The lowest concentration of the standard curve of the reference method was $3.5 \mu \mathrm{g} / \mathrm{ml}$.) In this study, the

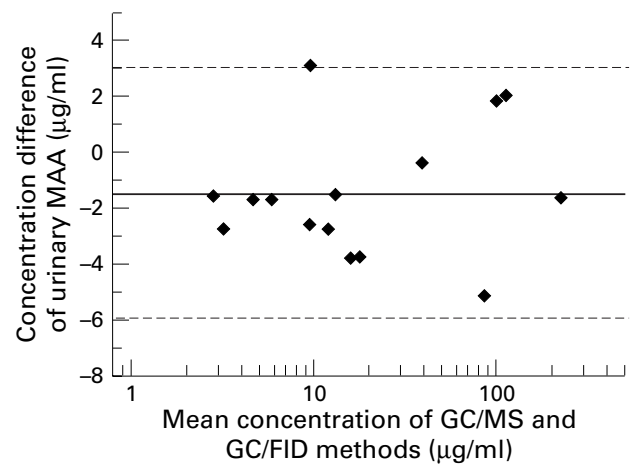

Figure 7 Concentration difference against the mean plot between GC/MS and GC/FID methods. The solid line represents the mean difference and dotted lines indicate the limits of agreement. difference in mean concentration and the limits of agreement were used to evaluate the agreement between the GC/MS method and the reference method. ${ }^{33}{ }^{34}$ The mean difference in concentration was $-1.48 \mu \mathrm{g} / \mathrm{ml}$; and the limits of agreement, mean (2 SD) concentration difference was $-6.06(3.09) \mu \mathrm{g} / \mathrm{ml}$, as shown in figure 7 .

\section{Discussion}

All conventional methods for urinary MAA, EAA, and BAA measurements use derivatisation procedures, which are expensive, hazardous, time and manpower consuming, and not universally reproducible for all congeners. Detection of MAA is especially difficult due to its poor extractability by simple organic solvents, bigger matrix effects, and the interfering effects of other organic acids. ${ }^{23}{ }^{24}$

Derivatisation increases sensitivity by introducing carbon for FID and halogen for ECD. Also, separation is facilitated by rendering the molecule less polar. The GC/MS, on the other hand, measures the analytes mainly by the abundance of major fragment ions. For GC/ MS, a bulky derivatisation molecule can generate a unique major fragment, but does not necessarily offer a better sensitivity. Thus, by choosing the appropriate fragment ion, we can omit the derivatisation procedures and still keep the equivalent sensitivity in the analysis of alkoxyacetic acid metabolites with the GC/MS method. The same lowest concentration of standard curve (the limit of reliable measurement), $0.3 \mu \mathrm{g} / \mathrm{ml}$, was found for the GC/MS method with and without trimethylsilyldiazomethane or pentafluorobenzyl derivatisation, which confirmed this hypothesis. With this simplified pretreatment of the samples, the sample preparation time can be shortened from $>10$ hours to 5 minutes for each sample, which makes the analysis much more efficient and more economic. Also fewer preparation steps will reduce error from sample handling.

The GC/MS has long been recommended as one of the most specific, and powerful analytical instruments for organic chemical analysis. With the rapid progress in manufacturing technology, the price of GC/MS has recently become very close to other traditional analytical methods-such as GC/FID. The slightly higher capital cost of GC/MS is compensated by the saving of expensive reagents, as well as the reduced time and manpower needed in the pretreatment procedures of the existing methods.

For simultaneous analyses of MAA, EAA, and BAA, the optimal extraction efficiency was obtained in the $\mathrm{pH}$ range of 1.05-1.45. Low $\mathrm{pH}$ value shifts more of the ionised alkoxyacetic acids to the non-ionised form, which increases the extraction efficiency. When $\mathrm{pH}$ reached 0.85 , however, the recovery of MAA decreased. This can probably be explained by the partial hydrolysis of MAA under very low $\mathrm{pH}$ conditions.

In our study, the matrix effect was nonsignificant for MAA and EAA, but was marginally significant for BAA $(0.2<p<0.5)$, even though the slope ratio of standard curves of BAA in urine and water was as high as 
0.911). The exact reason for this small discrepancy remains unclear. Endogenous electrolytes and elements in urine might cause a slight difference in extraction efficiency of BAA between urine and deionised water. Traditionally, analytical chemists tend to neglect the matrix effect when the slope ratio of standard curves in different matrices is $<10 \%$. The small SDs of the measurements also make the ANCOVA more sensitive to detect the small discrepancy in urine and water. It is therefore suggested that pooled urine samples from non-exposed workers be used to prepare the standard solutions to avoid the matrix effects.

The urinary MAA samples were stable for at least 5 months and 3 freeze-thaw cycles at $-20^{\circ} \mathrm{C}$. This is consistent with the finding of other studies that urinary EAA is stable for 8 months at $-20^{\circ} \mathrm{C} . .^{23}$

For method comparison, the correlation coefficient of the linear regression between the new GC/MS method and the reference method was very high $(r=0.999)$ with the $95 \%$ confidence interval $(95 \% \mathrm{CI})$ of the mean (2 SDs) including 1. The mean difference between the new method and the reference method is $-1.48 \mu \mathrm{g} / \mathrm{ml}$. These all indicate that a good agreement exists between the new GC/MS method and the current reference method. The true value of urinary MAA in exposed workers is never known, but the accuracy and precision of the reference method have been fully validated by other independent methods ${ }^{25}$ - namely, triplicate analysis samples, blind quality control samples, proficiency between laboratories of analyses testing the samples in this study, and field samples in other studies. ${ }^{25} 39$ The close agreement of this new GC/MS method with the reference method therefore indicates that the new GC/MS method is reliable for assessing the exposure to ethylene glycol ethers, and the GC/MS method is more sensitive and simpler than the reference method.

Most of the existing methods were developed to measure urinary alkoxyacetic acids. This new method has successfully been used to simultaneously analyse 2-methoxyethanol, 2-ethoxyethanol, and their main metabolites (MAA, EAA) in urine and blood samples in both exposed workers in field studies and in volunteers in our experimental studies (manuscripts in preparation).

It is therefore concluded that the simplified non-derivatisation pretreatment of samples coupled with GC/MS can provide a specific, sensitive, simple, safe, and reliable method for the biological monitoring of occupational exposure of ethylene glycol ethers.

We are indebted to Drs Paige Williams, Robert Herrick, David Christianin, Yoa-Pu Hu, and Ming Jen-Wu Chang, for their participation, discussion, and technical help. This work wa supported by the Institute of Occupational Safety and Health, Council of Labor Affairs, Executive Yuan, Taiwan, Republic of China. TJS was supported by Harvard Kresge Center for Environmental Health, NIESH grant ES00002.

1 National Institute for Occupational Safety and Health (NIOSH). Criteria for a recommended standard - Occupational exposure to ethylene glycol monomethyl ether, ethylene tional exposure to ethylene glycol monomethyl ether, ethylene glycol monothyl ether, and their acetates. Cincin
NIOSH, 1991. (Publication number 91-119.)
2 Nagano K, Nakayama E, Oobayashi $\mathrm{H}$, et al. Experimental studies on toxicity of ethylene glycol monomethyl ether in studies on toxicity of ethylene glycol monom

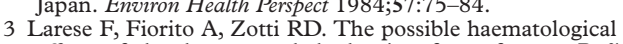
effects of glycol monomethyl ether in a frame factory. $\mathrm{Br} \mathcal{F}$ Ind Med 1992;49:131-3.

4 Wickramaratne GA. The teratogenic potential and doseresponse of dermally administered ethylene glycol monomethyl ether estimated in rats with the Chernoff-Kavlock assay. F Appl Toxicol 1986;6:165-6.

5 Welch LS, Schrader SM, Turner TW, et al. Effects of exposure to ethylene glycol ethers on shipyard painters: II. Male reproduction. Am f Ind Med 1988;14:509-26.

6 Welch LS, Cullen MR. Effects of exposure to ethylene glycol thers on shipyard painters: III. Hematological effects. Am f Ind Med 1988b;14:527-36.

7 Miller RR, Hermann EA, Langvardt PW, et al. Comparative metabolism and disposition of ethylene glycol monomethyl ether and propylene glycol monomethyl ether in male rats. Toxicol Appl Pharmacol 1983;67:229-37.

8 Moss EJ, Thomas LV, Cook MW, et al. The role of metabolism in 2-methoxy ethanol induced testicular toxicity. Toxicol Appl Pharmacol 1985;79:480-9.

9 Yonemoto J, Brown NA, Webb M. Effects of dimethoxyl phthalate, monomethoxyethyl phthalate, 2 -methoxyethanol and methoxyacetic acid on post-implanatation rat embryos in culture. Toxicol Lett 1984;21:97-102.

10 Miller RR, Carreon RE, Young JT, et al. Toxicity of methoxyacetic acid in rats. Fundam Appl Toxicol 1982;2: $158-60$

11 Sleet RB, Greene JA, Welsch F. The relationship of embryotoxicity to disposition of 2-methoxyethanol in mice. Toxicol Appl Pharmacol 1988;93:195-207.

12 Groeseneken D, Veulemas H, Masschelein R, et al. Experimental human exposure to ethylene glycol monomethyl ether. Int Arch Occup Environ Health 1989;61:243-7.

13 Rettenmeier AW, Hennigs R, Wodarz R. Determination of butoxyacetic acid and N-butoxyacetyl glutamine in urine of lacquerers exposed to 2-butoxyethanol. Int Arch Occup Environ Health 1993;65:S151-3.

14 Johanson G. Aspects of biological monitoring of exposure to glycol ethers. Toxicol Lett 1988;43:5-21.

15 Laitinen J, Liesivuori J, Turunen T, et al. Urinary biochemistry in occupational exposure of glycol ethers. Chemosphere 1994;29:781-7

16 Laitinen J, Liesivuori J, Savolainen H. Urinary alkoxy acetic acids and renal effects of exposure to ethylene glycol ethers. Occup Environ Med 1996;53:595-600.

17 Corley RA, Marham DA, Banks C, et al. Physiologically based pharmacokinetics and the dermal absorption of 2-butoxyethanol vapor by humans. Fund Appl Toxicol 1997; 39:120-30

18 Johanson G, Boman A. Percutaneous absorption of 2-butoxy ethanol vapor in human subjects. Br f Ind Med 1991;48:788-92.

19 Johanson G, Boman A, Dynesius B. Percutaneous absorption of 2-butoxy ethanol in man. Scand $\mathcal{F}$ Work Environ Health 1988;14: 101-9.

20 Groeseneken D, Van Vlem E, Veulemas H, et al. Gas chromatographic determination of methoxyacetic acid in urine Br F Ind Med 1986;43:62-5.

21 Groeseneken D, Veulemas $\mathrm{H}$, Masschelein R, et al. An improved method for the determination in urine of alkoxyacetic acids. Int Arch Occp Environ Health 1989b;61:24954.

22 Smallwood AW, Debord K, Lowry L. Analyses of ethylene glycol monoalkyl ethers and their proposed metabolites in

23 Smallwood AW, Debord K, Burg J, et al. Determination of urinary 2-ethoxyacetic acid as an indicator of occupational exposure to 2-ethoxyethanol. Appl Ind Hyg 1988;3:47-50.

24 Johanson, G. Analysis of ethylene glycol ether metabolites in urine by extractive alkylation and electron-capture gas chromatography. Arch Toxicol 1989;63:107-11.

25 Sakai T, Araki T, Masuyama Y. Determination of urinary alkoxyacetic acids by a rapid and simple method for biological monitoring of workers exposed to glycol ethers and their acetates. Int Arch Occup Environ Health 1993;64: $495-8$

26 Wittfoht W, Scott W, Nau H. Assay of methoxyacetic acid in body fluids and tissues by gas chromatography-mass spectrometry following tert-butyldimethyl silylation. 7 Chromatogr $1988 ; 448: 433-8$.

27 Berode M, Vernay A, Savolainen H. Liquid-solid phase extraction for quantitative alkoxyacetic acid analysis in extraction for quantitative alkoxyacetic acid analysis in urine. Proceeding of the International Symposium on Hea
Hazards of Glycol Ethers. Nancy, France: 1994:I-21.

28 Sohnlein B, Angerer J. A reliable and sensitive analytical method for the determination of six alkoxyacetic acids in urine. Proceeding of the International Symposium on Health Hazards of Glycol Ethers. Nancy, France: 1994:I-29.

29 Bormett G, Bartels MJ, Marham DA. Determination of 2-butoxy ethanol and butoxy acetic acid in rat and human blood by gas chromatography/mass spectrometry. $\mathcal{f}$ Chromatogr B Biomed Appl 1995;665:315-25.

30 Markham DA, Bartels MJ, Corley RA, et al. Analysis of 2-butoxyethanol and metabolites in human urine by GC and ESI/MS. 43 $3^{\text {rd }}$ ASMS Conference on Mass Spectrometry and Allied Topics [abstract WPG 170]. Atlanta, GA: Port and Allied Topics [abstract WPG 170]

31 National Institute of Occupational Safety and Health. Manual of analytical methods, 4th ed. Washington, DC: NIOSH, 1994. 
32 Harris RL, Cralley LJ, Cralley LV. Patty industrial hygiene and toxicology. Vol III, Part A, 3rd ed. New York: John Wiley and toxicology.

33 Bland JM, Altman DJ. Statistical methods for assessing agreement between two methods of clinical measurement. Lancet 1986;8:307-10.

34 Altman DG, Bland JM. Measurement in medicine: the analysis of method comparison studies. Statistician 1983 32:307-17.

35 Withdrawn.
36 Withdrawn.
37 Withdrawn.

38 Chang MJ, Shih TS, Chou JS. Method development for the biological monitoring of exposure to ethylene glycol monomethyl and monoethyl ethers. Taipei, Tiawan, Republic of China: Institute of Occupational Safety and Health, 1994. (Publication No 83-A207.)

39 Sakai T, Araki T, Morita Y, et al. Gas chromatographic determination of butoxyacetic acid after hydrolysis of conjugated metabolites in urine from workers exposed to 2-butoxyethanol. Int Arch Occup Environ Health 1994;66: 249-54.

\section{Correspondence and editorials}

Occupational and Environmental Medicine welcomes correspondence relating to any of the material appearing in the journal. Results from preliminary or small scale studies may also be published in the correspondence column if this seems appropriate. Letters should be not more than 500 words in length and contain a minimum of references. Tables and figures should be kept to an absolute minimum. Letters are accepted on the understanding that they be subject to editorial revision and shortening.

The journal also publishes editorials which are normally specially commissioned. The Editor welcomes suggestions regarding suitable topics; those wishing to submit an editorial, however, should do so only after discussion with the Editor. 